\title{
Der Amicus Curiae im Internationalen Wirtschaftsrecht
}

Eine rechtsvergleichende Untersuchung des U.S.-amerikanischen, deutschen, europäischen, Welthandels- und Investitionsschutzrechts sowie der Principles of Transnational Civil Procedure

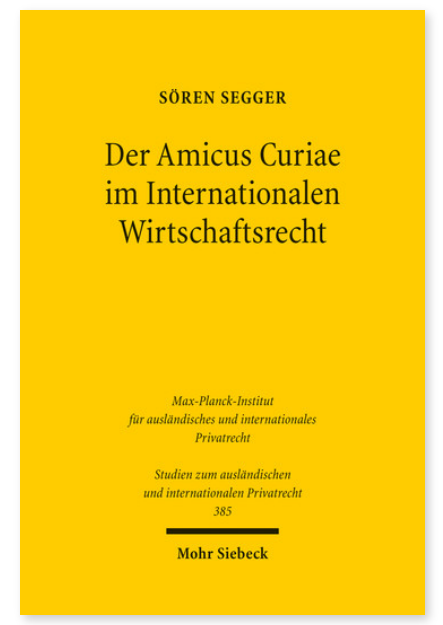

2017. XXX, 584 Seiten. StudIPR 385

ISBN 978-3-16-155162-8

DOI 10.1628/978-3-16-155162-8

eBook PDF 104,00 €

ISBN 978-3-16-155077-5

fadengeheftete Broschur 104,00€
Das Rechtsinstitut des amicus curiae ist insbesondere aus dem U.S.-amerikanischen Recht bekannt: Ein am Prozess an sich unbeteiligter Dritter gibt dem Gericht eine Stellungnahme ab mit Informationen über Hintergrund oder Umfeld der zu entscheidenden Frage. Mittlerweile sind amici in einer Vielzahl unterschiedlicher Rechtsordnungen geläufig. Sören Segger untersucht auf breiter rechtsvergleichender Grundlage eingehend die prozessualen Einzelfragen einer amicusBeteiligung: Was sind die Voraussetzungen einer Beteiligung? Wann ist eine amicus-Stellungnahme einzureichen? Können tatsächliche Informationen als Beweis verwertet werden? Welche Rolle spielt hierbei der Beibringungsgrundsatz? Welche prozessualen Rechte hat ein amicus? Neben der Erörterung einer Vielzahl weiterer Fragen wird auch geprüft, inwiefern das Institut des amicus nicht auch in das deutsche und europäische Prozessrecht übertragen werden sollte.

Sören Segger Geboren 1985; Studium der Rechtswissenschaft in Würzburg; 2010 Erste Juristische Prüfung; wissenschaftlicher Mitarbeiter am Lehrstuhl für Bürgerliches Recht, Europäisches Wirtschaftsrecht, Internationales Privat- und Prozessrecht sowie Rechtsvergleichung der Universität Würzburg; Referendariat in Wuppertal, Düsseldorf und Bonn; Rechtsanwalt in Düsseldorf; seit 2016 wieder wissenschaftlicher Mitarbeiter am oben genannten Lehrstuhl in Würzburg.

Jetzt bestellen:

https://mohrsiebeck.com/buch/der-amicus-curiae-im-internationalen-wirtschaftsrecht-9783161551628?no_cache=1 order@mohrsiebeck.com

Telefon: +49 (0)7071-923-17

Telefax: +49(0)7071-51104 